\title{
Màgia i fantasia al servei de les nobles nissagues: el cas de Nofra- dona Dolcina en la novel la històrica de Vicent Josep Escartí
}

\section{Magic and fantasy at the service of noble lineages: the case of Nofra- dona Dolcina in Vicent Josep Escarti's historical fiction}

\author{
M. ÁngeLes Herrero Herrero \\ mangherr@gmail.com
}

Universitat d'Alacant

\begin{abstract}
Resum: Dos dels elements més identificables en la novel la històrica de Vicent Josep Escartí són, per una banda, el component màgic i fantàstic i, per una altra, l'existència de dues nobles nissagues: els Roger i els Arcàngel de Sant Esteve. De fet, la primera ja s'apuntà subtilment en «El fill de Gepa» i es desenvolupà en «Epistolari del Comte de l'Hortxà», primer i segon relat de Barroca mort (1988). Posteriorment, s'estengué a Dies d'ira (1992) -Days of Wrath (2013)-, Els cabells d'Absalom (1996), Nomdedéu (2002), Naumàquia (2004) i El mas de les ànimes (2019). Amb Espècies perdudes (1997) sorgí el segon llinatge, que continuà en L'abellerol mort (2009), en les quals els Roger també s'endinsen enginyosament. Però, si hi ha un enllaç directe entre ambdues nissagues i que, alhora, encarna el joc fantàstic amb què Escartí impregna la seua obra, són els personatges -secundaris- de Nofra-dona Dolcina. L'objectiu de l'article serà fer un recorregut per la seua novel lística gràcies a aquests personatges femenins, els quals serviran per constatar-hi la importància de la màgia i la fantasia. Amb el protagonisme d'una dona en la seua darrera novel la, El mas de les ànimes, ho torna a posar de manifest.
\end{abstract}

Paraules clau: novel la històrica valenciana, Escartí, nissagues, personatges femenins, màgia, fantasia.

\begin{abstract}
Two of the most easily identifiable elements in Vicent Josep Escarti's historical fiction are, on the one hand, the magical and fantastic component and, on the other hand, the existence of two noble lineages: the Roger family, and the Arcàngel de Sant Esteve family. In fact, the first one subtly appeared already in «El fill de Gepa» and developed in «Epistolari del Comte de l'Hortxà» -the first and second story within Barroca mort (1988). It subsequently spread to Dies d'ira (1992) - Days of Wrath (2013)-, Els cabells d'Absalom (1996), Nomdedén (2002), Naumàquia (2004) and El mas de les ànimes (2019). Espècies perdudes (1997) marked the emergence of the second lineage, which continued in L'abellerol mort (2009), where the Roger family are ingeniously introduced as well. Nevertheless, if a direct link exists between both lineages which simultaneously embodies the fantastic play that pervades Escarti's work, those are the -secondary- characters of Nofra-dona Dolcina. This article has as its purpose to make a tour of his novels thanks to these female characters, which will help verify the important role that magic and fantasy play in them. Escartí stresses this once again through the prominence of a woman in his latest novel, El mas de les ànimes.
\end{abstract}

Keywords: Valencian historical fiction, Escartí, lineages, female characters, magic, fantasy.

\footnotetext{
* Aquest treball s’emmarca en el projecte d’investigació «Biografías marginales: violencia, sexo, género e identidad. Edición y análisis de fuentes documentales valencianas de la Época Foral» (PGC2018-097011-B-I00) del Ministerio de Ciencia, Innovación y Universidades del Gobierno de España.
} 


\section{M. Ángeles Herrero Herrero. Màgia i fantasia al servei de les nobles nissagues: el cas de Nofra- dona Dolcina en la novel la històrica de Vicent Josep Escartí}

«Allà, nu, imaginava el meu fill gestant-se al ventre de la dona que tenia davant

(Escartí 2009: 239)

«Jo, quasi tremolós, no sabia si allò que veia era cert o no».

(Escartí 2009: 250)

«Puix que sou gran advocat / contra misèries i plors, / procureu-nos, per pietat, / el bé del Nostre Senyor!»

(Escartí 2019: 84)

\section{Introducció}

Vicent Josep Escartí és, sens dubte, un dels principals representants de la novel la històrica valenciana a hores d'ara. Un autor ja consolidat, amb un total de nou novel les, ${ }^{1}$ que compta amb el reconeixement de la crítica gràcies a guardons com l'últim rebut, el Premi Enric de Valor de Novel la 2018 a la recentment publicada El mas de les ànimes (2019). En anteriors ocasions ens havíem acostat a la seua producció novel lística amb el fi d'analitzar els recursos narratius emprats (Herrero 2004 i 2007ab), en la qual el lector ha d'entrar en un pacte novel lesc on hi ha la noidentitat (entre autor i personatge) com afirma Lejeune (1994: 65).

Les seues novel les presenten una ambientació històrica recognoscible i una contextualització geogràfica concreta, principalment a València, a les comarques centrals, i a l'extensió fictícia de la Roca delimitada «en els quatre cantons de l'estat dels Roger, que incloïa Montdrach, les Eres, la Font Negra i la Vilanova» (Herrero: 2017: 281). ${ }^{2}$ D'aquesta forma, «el pastitx entre l'ambientació històrica i les tècniques autobiogràfiques esdevé un mitjà estilístic que atorga credibilitat al relat» (Herrero 2015: 279). Però, són narracions que, sobretot, se suporten en un grapat de personatges protagonistes i secundaris, en qui «Escartí creu fidelment (...), els comprén i és capaç de contemplar

1 Exceptuem d'aquesta anàlisi el relat Vent de juliol (1989). Com ja vam apuntar (Herrero 2015: 280, n. 2), es tracta d'una contalla ambientada en el renaixement valencià sobre una història de la Germania, malgrat que presenta els trets més característics de la seua producció com és l'ambientació històrica i geogràfica i, alhora, té punts de connexió amb Nomdedéu (2002), no entronca amb les nissagues Roger i Arcàngel. Però, cal tindre en compte un altre relat, «El retrat anònim» (2016), publicat en tres parts, tot i que a priori pareix no tenir relació amb aquestes nissagues, sí trobem algun episodi paral lel en la seua última novel la, El mas de les ànimes.

2 Tot i que també hi ha alguns breus episodis que s'esmenten en Espècies perdudes i L'abellerol mort fora de territori valencià (Xipre, Itàlia, Sevilla i Madrid). 


\section{M. Ángeles Herrero Herrero. Màgia i fantasia al servei de les nobles nissagues: el cas de Nofra- dona Dolcina en la novel la històrica de Vicent Josep Escartí}

la història que protagonitzen des de l'interior de cadascun d'ells» ${ }^{3}$ (Herrero 2015: 290). Eixa aproximació ens havia fet veure que la seua tria no era fortuïta, ans al contrari: «les biografies dels nobles personatges escartians estan subjugades a la modalització del relat» (Herrero 2017: 289). Ara bé, per tal de poder entendre la complexitat de la ficció de l'autor d'Algemesí en la seua globalitat, cal recordar que, malgrat que estem al davant de novel les independents, són complementàries alhora (Herrero 2007a: 260). ${ }^{4}$ Això suposa que un estudi monogràfic d'una de les seues obres sempre obligarà a precisar quin n'és el grau de connexió amb la resta.

\section{La novel lística escartiana a través de dues nissagues: els Roger i els Arcàngel}

L'entrada al món fictici d'Escartí «implica estar contínuament alerta a les seues picades d'ull, si volem ser partícips de dues megaxarxes biogràfiques» (Herrero 2015: 290): els Roger i els Arcàngel de Sant Esteve. La intencionalitat de creació d'una branca familiar, concretament la dels Roger, és confessa des de Dies d'ira (1992) -escrita en forma de memòries, i publicada en anglés als Estats Units com Days of Wrath (2013) - (Herrero 2017: 280). Tanmateix, la nissaga ja era suggerida, tot $\mathrm{i}$ que de forma molt subtil, en la contarella fantàstica «El fill de Gepa», el primer relat de Barroca mort (1988). ${ }^{5}$ Aquesta rondalla està centrada a la Ribera del Xúquer entre 1648 i 1652 (Herrero 2007a: 250), el «protagonista-monstre» de la qual, narrador al mateix temps, podria tenir una procedència nobiliària: «Acabat de parir, ma mare, esglaiada en mirar-me, em llançà al riu dalt d’un garbó de canyes», i va ser recollit per «aquell home a qui sempre vaig dir pare» (Escartí 1988: 35), com ja vam assenyalar en un estudi anterior (Herrero 2015: 283-284). Potser el fill de Gepa era un Roger, però la seua una imatge «tan poc agraciada com poques se n’han vist» (Escartí 1988: 27) no el feia digne de dur el cognom d'una de les nissagues «més distingides i nobles de tot el Regne de València» (Escartí 2002: 78). ${ }^{6}$ En el segon dels relats de Barroca mort, «Epistolari del comte de l'Hortxà», ambientat entre 1647 i 1648, els Roger de la Roca són circumstants en el succés de l'arribada de la pesta a València, atés que les dades biogràfiques dels personatges queden en un segon pla $\mathrm{i}$ «allò que predomina en el relat és l'ambientació historiogràfica» (Herrero 2015: 283-284).

3 Fet que es torna a posar de manifest amb la protagonista d'El mas de les ànimes.

4 Complementàries i interdependents per les branques familiars que hi participen. El cas més evident és el de les novel les Espècies perdudes (1997) i L'abellerol mort (2009), primera i segona part, protagonitzades per pare i fill, nobles xipriotes Arcàngel de Sant Esteve (Herrero 2015: 285).

5 Per a un estudi més detallat de l'obra vegeu Herrero (2007a: 255-258 i 2015: 281-282).

6 A més a més, els i les Roger tenien uns trets molt remarcables i agradables a la vista com s'expliciten en alguns de relats. Així són descrits en Nomdedéu (Escartí 2002: 46,20) dos dels membres més destacats de la nissaga, per un costat, donya Isabel Roger i Llançol, una bella dona amb «cabells rossos ben pentinats i adornats amb unes poques perles bé que denunciaven els seus avantpassats Roger»; i per un altre, el seu espòs don Baltasar Roger i Romaní, comte de la Roca i l'Hortxà: «la pell blanquíssima de tots els Roger i les galtes fresques (...): els cabells, rossos, llargs i recollits amb un llaç roig, eren lluents». Aquestes descripcions podrien servir de model a la resta de membres del seu llinatge.

SCRIPTA, Revista internacional de literatura i cultura medieval i moderna, núm. 14/desembre 2019/ pp. 316 - 328 ISSN: 2340-4841 · doi:10.7203/SCRIPTA.14.16373 


\section{M. Ángeles Herrero Herrero. Màgia i fantasia al servei de les nobles nissagues: el cas de Nofra- dona Dolcina en la novel la històrica de Vicent Josep Escartí}

A mesura que Escartí publica una novel la, l'arbre genealògic dels Roger s'estén i creix davant dels nostres ulls. Així, Dies d'ira (1992), escrita en forma de memòries, és protagonitzada per un Roger, don Jeroni Joan, tercer fill del comte de Montdrach, i relatada en dos temps: el dels esdeveniments narrats, 1547, i el de la confessió dels fets pel protagonista-narrador durant els anys 1615 i 1616 (Herrero 2015: 281). ${ }^{7}$ Els esdeveniments ocorreguts en Dies d'ira són esmentats posteriorment en la novel la Nomdedéu (2002), amb el protagonisme, per una banda, del matrimoni de don Baltasar Roger i Romaní i donya Isabel Roger i Llançol i, per una altra, de l'angèlic Cosme Nomdedéu, vassall i protegit dels Roger, qui serà «la clau per a la perpetuació de la nissaga» (Herrero 2015: 282). 9 Ara bé, Els cabells d'Absalom (1996) -una autobiografia fantàstica-, Espècies perdudes (1997) -un dietari en l'exili-i L'abellerol mort (2009) - unes memòries- no estan protagonitzades per un Roger, ${ }^{10}$ tot i que aquesta nissaga s'endinsa de manera molt enginyosa en les tres obres (Herrero 2015: 285), gràcies a la relació directa amb un membre del llinatge Roger ${ }^{11} \mathrm{com}$, per exemple, el protagonista d'Els cabells d'Absalom, Melcior d'Agramunt, ${ }^{12}$ es presenta com a escrivà i secretari del comte de la Roca.

És en Espècies perdudes (1996), ambientada a Xàtiva entre 1763 i 1764, on sorgeix la nissaga dels Arcàngel de Sant Esteve ${ }^{13}$ a través del seu protagonista, el seté n'Arcàngel Gabriel megaduc de Sant Esteve, qui dicta les seues memòries a un majordom. ${ }^{14}$ La història dels Arcàngel té la seua

7 També s'apunten altres passatges de la infantesa de don Jeroni Joan, en 1539 i en l'adolescència de 1542 (Herrero 2015: 281, n. 7). Vegeu Herrero (2007a: 250) per a més detalls sobre la novel la.

8 A propòsit d'unes noves obres del palau el 1553 per l'elecció d'un net com a hereu (Escartí 2002: 76-77). Alhora, l'arribada de la pesta enllaça amb els relats de Barroca mort (Herrero 2015: 283).

9 Nomdedéu es desenvolupa en onze capítols, en tercera persona, a excepció de dos: el VIII, amb la vida del personatge Cosme Nomdedéu dictada per ell mateix, i l’XI, pròleg-dedicatòria al comte don Baltasar, escrit per mossén Lluís (Herrero 2015: 282, n. 10).

10 En aquestes dues novel les el llinatge dels Roger també és partícip dels esdeveniments dels Sant Esteve. El seté Arcàngel té relació amb dos Roger: el notari Felip Maria Guzman de Villar, parent dels comtes de Montdrach, i fra Rafael de la Roca, de la Cartoixa de Trànsit de Crist, precisament el monestir on es troba el protagonista de Dies d'ira (Herrero 2015: 287). El vuitè Arcàngel té també contacte amb el senyoriu de la Roca quan visita la casa de don Baltasar Cosme Roger i Castellbò de les Jovades i dona Constança de Castellflorido. Ja vam assenyalar que aquests personatges connecten directament amb la novel la Nomdedéu (Herrero 2015: 288, n. 25).

11 Vegeu Herrero (2007b i 2015) per a una anàlisi més detallada de l'obra.

12 Agramunt recorda els passatges més significatius de la seua vida i el procés inquisitorial de l'any 1622 (Herrero 2015 : 285). Vegeu també Herrero (2007a: 255-258).

13 Aquesta nissaga té el seu origen amb «el primer Sant Esteve que arribà a l'Illa», el qual «provenia del mateix regne d'Aragó (...) i aquell acompanyava la reina Elionor, l'esposa del rei Pere; (...) el meu parent fundador a l'Illa (...) a l'igual que el seu fill (...) no passaven de ser escrivans de palau» (Escartí 1997: 14).

14 L'exili es deu al suport i lleialtat al monarca Jaume VIII dels Lusignans de Xipre. Ja vam explicar que aquest personatge només podia existir si Xipre, en el segle XVIII, no hagués estat sota el domini de l'Imperi Otomà. Vegeu

SCRIPTA, Revista internacional de literatura i cultura medieval i moderna, núm. 14/desembre 2019/ pp. 316 - 328 ISSN: 2340-4841 · doi:10.7203/SCRIPTA.14.16373 


\section{M. Ángeles Herrero Herrero. Màgia i fantasia al servei de les nobles nissagues: el cas de Nofra- dona Dolcina en la novel la històrica de Vicent Josep Escartí}

continuïtat en la novel la L'abellerol mort (2009), escrita igualment en forma de memòries, en aquesta ocasió pel seu fill, el vuitè n'Arcàngel «gran duc de Sant Esteve», la història de la qual transcorre durant 1765 i 1766, un any i uns mesos després dels fets ocorreguts en Espècies perdudes. Si de la petja dels Arcàngel ja no tenim més notícia i, fins i tot, dubtem de si està garantida la seua perpetuació després del vuitè Arcàngel de Sant Esteve, com explicarem més endavant, ${ }^{15}$ en canvi, la dels Roger perviu fins als nostres dies amb la figura de Gaspar Ferrer, actant i circumstant en la novel la Naumàquia (2004), escrita en tercera persona, quan la nissaga ja està allunyada de l'esplendor de segles passats. Aquesta obra és «atípica dins el món escartià perquè està ambientada en els nostres dies» (Herrero 2015: 288). ${ }^{16}$ Amb la publicació de la seua darrera novel la, El mas de les ànimes, també escrita en tercera persona, amb una mescla de narrador omniscient i d'observador, Escartí retorna als dominis dels Roger, al mas de les Moreres, a les «serralades de Montdrach i la Roca» (Escartí 2019: 17), en una època que encara no havia estat filtrada pel seu prisma: del 1799 fins al $1936 .{ }^{17}$

En altres ocasions hem puntualitzat que els subjectes que són membres de les nissagues dels Roger i dels Arcàngel no són els únics actants i circumstants de les seues novel les (Herrero 2015: 280), sinó que l'autor, a mesura que avança en la seua particular trajectòria literària, enriqueix el seu món fictici. En aquest sentit, hi ha altres personatges secundaris, periferics, que en un determinat moment poden adquirir una rellevància singular en el desenvolupament de la trama.

\section{La personificació de la màgia i la fantasia: Nofra-dona Dolcina}

Nofra-dona Dolcina, un doble personatge, un personatge desdoblat o un personatge calidoscòpic té un important component simbòlic en la seua novel lística i evidencia la connexió màgica $i$ fantàstica més directa entre ambdós llinatges. Cal precisar que en la literatura escartiana gairebé no hi ha protagonistes femenines com a tal, si exceptuem alguns casos puntuals: el de donya Isabel Roger i Llançol, qui comparteix protagonisme amb el seu marit don Baltasar Roger i amb Cosme Nomdedeu $^{18}$ en la novel la Nomdedéu, el d'Evangelina -ex-muller de Gaspar Ferrer- en alguns

Herrero (2007b; 2015: 285-287).

15 Com suggereixen els títols de les dues novel les que protagonitzen els Arcàngel. Vegeu Herrero (2015: 288).

16 Per a més detalls sobre l’obra vegeu Herrero (2015: 288-289).

17 El protagonisme, però, no és dels Roger, sinó que som coneixedors d'altres nissagues: la dels Domingo -els de la marca Llançada de Nostre Senyor- i la dels Palop de la Roca. Les noves famílies, com altres que apareixen en la seua novel lística, els Malea -en Espècies perdudes- i els Llançol -en Nomdedéu-, encara que aquestes dues són esmentades fugaçment, comparteixen vincles amb els Roger i els Arcàngel i demanen una anàlisi més profunda per a entendre el gruix de la novel la.

18 Aquest personatge dona nom a un dels secundaris d'El mas de les ànimes, Cosme Palop, a qui «posaren aquell nom els seus pares per la gran devoció que hi havia al poble a les restes del venerable beat Cosme Nomdedeu, que descansava en pau en el temple parroquial» (Escartí 2019: 84). Es tracta, per tant, d'una altra connexió amb la nissaga dels Roger.

SCRIPTA, Revista internacional de literatura i cultura medieval i moderna, núm. 14/desembre 2019/ pp. 316 - 328 ISSN: 2340-4841 · doi:10.7203/SCRIPTA.14.16373 
M. Ángeles Herrero Herrero. Màgia i fantasia al servei de les nobles nissagues: el cas de Nofradona Dolcina en la novel la històrica de Vicent Josep Escartí

episodis de la singular Naumàquia, el d'Eufrosina de l'Esperit Sant en el relat breu en tercera persona «El retrat anònim», i el cas més excepcional i, el de Maria Celidònia del Socors Perpetu Palop Alemany ${ }^{19} \mathrm{~d}^{\prime} E l$ mas de les ànimes. ${ }^{20}$ Però, sí que s'ha d'assenyalar que alguns dels seus personatge femenins adquireixen un rol fonamental: el de la perpetuació de les nissagues.

Sánchez (1998: 97) indica que «el lector debe construir las diferentes unidades "personaje" por los signos de coherencia que el narrador va ofreciendo de forma aislada y discontinua». Aquesta afirmació pren tot el sentit en el cas de Nofra-dona Dolcina, atés que personifica una espècie de subjecte-trencaclosques en el món literari escartià. Per una banda, hem de parlar de Nofra, personatge de Dies d'ira, l'obra protagonitzada per don Jeroni Joan Roger, relatada als segles XVI i XVII, i per una altra, de dona Dolcina de L'abellerol mort, amb el vuitè n'Arcàngel Gabriel de Sant Esteve com a protagonista, ambientada a la segona meitat del segle XVIII. És important subratllar que L'abellerol mort té un deute innegable amb Dies d'ira per diferents raons: en primer lloc, les dues novel les estan relatades en forma de memòries per dos protagonistes que són autors d'uns actes gravíssims; en segon lloc, la trama narrativa circula al voltant d'un assassinat; en tercer lloc, hi ha un paral lelisme evident en alguns episodis - com la febre que pateixen els protagonistes, l'arribada de la plaga de llagostes, etc.-; i en quart i últim, per la presència, simbòlica, de Nofra-dona Dolcina. De fet, la novel la del 2009 és, «en cert, mode, una rememoració de l'obra publicada el 1992» (Herrero 2015: 287). Tanmateix, les memòries són escrites amb diferent propòsit: mentre que en Dies d'ira s'usen a mode d'expiació dels pecats, en L'abellerol mort serveixen «de testament i darrera confessió» per a poder copsar una realitat marcada, sobretot, pels esdeveniments estranys $i$ inexplicables que protagonitza dona Dolcina.

Nofra, com hem esmentat adés, és un personatge secundari en Dies d'ira. Però, aquest nom apareix per primera vegada en Barroca mort. Més concretament, en la narració d'«El fill de Gepa». No obstant això, no podem assegurar que es tracta de la mateixa «Nofra» perquè no hi ha indicis clars que ho corroboren. En el primer relat de Barroca mort Nofra és «una fadrina de l'alqueria de Xara» on havia entrat a servir ja prenyada per l'engany del seu germà, Baptista. Ella, malauradament «parí un ésser estrany»-que morí unes hores després- «amb dues natures, una davant i l'altra darrere i, a l'esquena, també tenia dues mamelletes xicotetes. Enmig del front tenia un ull molt clar que s'obria i es tancava com els altres dos que, per contra, eren foscos i molt petits». La mort de la criatura desencadenà una tempesta horrible, una fatalitat que creà entre la gent del poble un ambient de superstició, perquè soterrar-lo allí «deien que (...) portaria desgràcies», fins al punt que d'allò «es parlà durant molts anys i (...) s'estengué per tot aquest regne i, encara, molts astròlegs digueren

19 Hi ha un altre personatge en la seua novel lística que gairebé comparteix el nom, però amb qui no hem de confondre: dona Maria Celidònia del Perpetu Socors, casada amb un Simó, besàvia del seté Arcàngel Gabriel de Sant Esteve, «la qual no passà dels quaranta anys mai i en morir - d'edat de prop de cent anys- es conservava tan jove i fresca i bella com aquell dia que eixí de les quartanes». Vegeu Escartí (1997: 95, 152).

20 També podríem afegir les tres dames valencianes del segle XVI que coprotagonitzen amb Açmet el relat Vent de juliol.

SCRIPTA, Revista internacional de literatura i cultura medieval i moderna, núm. 14/desembre 2019/ pp. 316 - 328 ISSN: 2340-4841 ·doi:10.7203/SCRIPTA.14.16373 


\section{M. Ángeles Herrero Herrero. Màgia i fantasia al servei de les nobles nissagues: el cas de Nofra- dona Dolcina en la novel la històrica de Vicent Josep Escartí}

que allò volia anunciar la pesta i les grans malures que després van venir» (Escartí 1988: 32-33). El fill de Gepa relata que ella i el seu germà «se n'anaren -uns diuen que a Castella i, altres, que d'allí volien encaminar-se a Sevilla per salpar cap a les Índies» (Escartí 1988: 33) ${ }^{21}$ En el segon dels relats de Barroca mort, «Epistolari del comte de l'Hortxà» apareix de manera fugaç un altre personatge circumstant amb el nom de Nofra, de mà del comte don Tomàs Francesc de l'Hortxà. Don Tomàs escriu la segona de les epístoles al seu germà don Carles, comte de la Roca, datada a València el 20 de novembre de 1647, en què li conta: «Ahir (...) s'emportaren una de les fadrines dels nostres cosins, els Roger - una que es deia Nofra-, a la casa de Troia, que és l'hospital del qual tenen cura els dominics, i a la nit ja era morta» (Escartí 1989: 90). Com hem dit adés, no és clar que aquestes dues «Nofres» estiguen relacionades entre sí, ni tampoc tinguen a veure amb la que prendrà un major protagonisme en Dies d'ira, però no ho podem descartar a causa de la fantasia amb què impregna l'autor els seus relats.

La Nofra de Dies d'ira i dona Dolcina de L'abellerol mort tenen unes característiques extremadament particulars que fan relacionar-les entre si. Ambdues actuen de fitxes de puzle ${ }^{22}$ en la trama argumental i en la xarxa de connexions entre els subjectes d'una part important del món literari escartià. L'autor proposa un joc intrínsec de què només és conscient aquella/a que llig més d'una de les seues novel les. Aquest fet obliga el lector, per tant, a estar alerta contínuament i/o a rellegir-les per tal de descobrir els possibles enllaços entre els diferents relats. D’una altra forma no podrà adonarse del treballat teixit de correspondències entre els individus que circulen pel seu univers. A més a més, no hi trobem «una biografia contada de forma lineal, sinó que les seues vides s'hi mostren a pinzellades, sense un ordre lògic, perquè depenen de l'acció que mou el personatge-protagonista dins la història» $\mathrm{i}$ «la trama sovint és narrada a través de retrospeccions o flasbbacks» (Herrero 2015: 289).

Nofra i dona Dolcina no presenten uns trets típics ni tòpics en la seua obra, ni per descomptat, en una novel la històrica tradicional en què no brolla el referent màgic i fantasiós. Hi estan subjugades per al seu desenvolupament dins del discurs narratiu. Són subjectes que, analitzades de manera individual, esdevenen antagòniques. I tant és així que, si en Dies d'ira Nofra és un personatge estàtic i pla perquè «atraviesa experiencias, pero sus cambios no borran o corrigen la decisión con que han sido trazados», en L'abellerol mort dona Dolcina és dinàmic i redó, ja que el seu «carácter (...) va moldeándose» (Sánchez 1998: 102) i

cuando acaba la novela ya no [es] igual que cuando empezó: ha cambiado. Es capaz de sorprendernos y, a la vez, de convencernos de que esa sorpresa era inevitable. (...) es mucho más rico y complejo, está mucho más elaborado, tanto interna como externamente (Sánchez 1998: 103).

21 Dona Dolcina, personatge de L'abellerol mort, confessa que s'havia fet passar per diferents dones amb diversos noms, un d'aquest és el de dona Nofra, i que havia marxat a Sevilla en un determinat moment. Vegeu Escartí (2009: 196-198).

22 Com les microhistòries que són relatades en Naumàquia. Vegeu Herrero (2015: 288).

SCRIPTA, Revista internacional de literatura i cultura medieval i moderna, núm. 14/desembre 2019/ pp. 316 - 328 ISSN: 2340-4841 · doi:10.7203/SCRIPTA.14.16373 


\section{M. Ángeles Herrero Herrero. Màgia i fantasia al servei de les nobles nissagues: el cas de Nofra- dona Dolcina en la novel la històrica de Vicent Josep Escartí}

Teòricament, la caracterització del personatge inclou tres aspectes: la identitat física, els seus hàbits i la seua conducta i els vincles amb la resta de personatges (Sánchez 1998: 99-100). Així doncs, Nofra és una «vella esclava negra», al servei de don Jeroni Joan Roger al segle XVI en Dies d'ira, amb la «cara tan negra i lletja, encerclada pels blancs i desfets cabells» ${ }^{23}$ (Escartí 1993: 38), que parlava «la llengua del país dels Negres d'on ella provenia" (Escartí 1993: 40). És una dona-víctima, ${ }^{24}$ submisa, que guarda el secret de l'assassinat comés pel seu amo don Jeroni Joan (Escartí 1993: 41) i acata, amb una barreja d'estima -com «si fósseu fill meu, el fill que mai no he pogut parir, en aquesta terra que no és la meua» (Escartí 1993: 41)-, de resignació i de temor, les seues ordres. Té un caràcter dòcil com mostra quan ha de practicar-li una mena d'exorcisme per llevar-li la febre amb la invocació dels «seus déus i fent les seues bruixeries (...) si no volia que la denunciàs i el seu cos acabàs a la foguera, que és on ja feia anys que hauria d’haver anat» (Escartí 1993: 39). És un ésser subjugat a la condició humana, però amb nobles intencions: «i i com penseu que jo puga fer desaparèixer ossos de notari? ¿És que per ventura creieu que soc santa o bruixa, i puc fer el món al meu plaer?» (Escartí 1993: 135). Però, sobtosament, Nofra és embolcallada per l'ingredient màgic i fantasiós: ascendeix al cel i desapareix: «se l'havia duta la nuvolada de les llagostes, carregada com anava amb els ossos del meu notari $\gg^{25}$ (Escartí 1993: 151). El final de Nofra es queda, per tant, obert.

Tanmateix, la presència d'una dona misteriosa en L'abellerol mort ${ }^{6}$ ens convida a jugar obertament a «qui és qui?». Des del començament de les memòries del vuité n'Arcàngel Gabriel, ell mateix ens confessa el pes que eixe personatge femení tindrà en la seua història: «va ser la desaparició de dona Dolcina, de la seua pell lluenta i càlida, de la seua saliva dolça i espessa, de la seua suor acre i confortativa, el que em va portar a una realitat que ja no sabia ni volia explicar-me», perquè quan «va aparèixer en la meua vida, tot es va anar precipitant com un grandíssim salt d'un rierol encaixonat entre penya-segats» (Escartí 2009: 5-6). Dona Dolcina Cirlot, la marquesa Maltrobada, és una misteriosa i bella dama de pell negra, una mena de dona-venjadora, ${ }^{27}$ amagada sota «tal quantitat de pólvores d'arròs sobre la pell i ungüents i cosmètics de l'índole més diversa» (Escartí 2009: 165) i roba fina ${ }^{28}$ que encisa i ompli de desig n'Arcàngel Gabriel de Sant Esteve al segle XVIII.

23 En Nomdedéu (Escartí 2002: 94) hi ha l’aparició de «la negra Quitèria que parlava la seua estranya llengua quan se sentia malhumorada», com una de les dones que fan companyia donya Isabel Roger i Llançol. Aquest tret físic no és compartit amb les «Nofres» de Barroca mort.

24 Usant les tipologies femenines de l'estudi de Mulet (1991: 59) per a l'anàlisi de l'obra de Maria Ibars.

25 Però «els ossos de Carles Miquel Descó foren trobats al monestir de Trànsit-de-Crist, on foren deixats per la plaga, en passar per dalt» (Escartí 1993: 151).

26 Sobretot acapara la seua atenció en dos capítols de la novel la: V. «De l'amor de dona Dolcina» i VI. «De l'arribada de les llagostes i del relat de la vida de dona Dolcina».

27 Vegeu nota 24.

28 Així ho descriu el vuité Arcàngel de forma més detallada: «a pesar que mai li havia pogut veure ni una llesca mínima de la seua persona, més enllà dels seus ulls negres i grans, lluents, i del seu rostre pàl lid i empolvorat, blanc d'afaits,

SCRIPTA, Revista internacional de literatura i cultura medieval i moderna, núm. 14/desembre 2019/ pp. 316 - 328 ISSN: 2340-4841 · doi:10.7203/SCRIPTA.14.16373 


\section{M. Ángeles Herrero Herrero. Màgia i fantasia al servei de les nobles nissagues: el cas de Nofra- dona Dolcina en la novel la històrica de Vicent Josep Escartí}

Dona Dolcina i el seu alter ego, Nofra, en Dies d'ira, personifiquen el realisme màgic en respectives novel les. A més a més, Dolcina esdevé el contrapunt del vuité Arcàngel de Sant Esteve, perquè «al contrari que el seu progenitor [el seté Arcàngel d'Espècies perdudes], (...) s'allunya de les supersticions, és escèptic de tot allò que no respon a la lògica (...) és coherent amb un individu de la segona meitat del segle XVIII» (Herrero 2015: 287-288). En aquest sentit, el vuitè n’Arcàngel Gabriel és, al mateix temps, el contrast de don Jeroni Joan Roger: un individu condicionat pel trinomi Religió/ Tradició/Superstició de què parlava Borràs (1989: 14) en l'anàlisi de Barroca mort. Cal recordar que el joc màgic ja sorgia en el primer relat de la dita novel la a través del narrador, el fill de Gepa, el «protagonista-monstre» que també tenia uns dons especials fruit de la màgia o de la bruixeria. ${ }^{29}$ Així doncs, com afirmava Simbor (1996: 115), la seua obra s'emmarca en el subgènere fantasticointel lectual, ${ }^{30}$ un «joc dels esdeveniment i personatges històrics amb els de la fantasia i la imaginació» que, fora de ser un recurs puntual, és recurrent en els seus relats i sovint es materialitza en algun dels seus personatges. Per això no són novel les històriques tradicionals, cosa que ens fa tenir molt present eixe trinomi que esmentava Borràs. Ara bé, la màgia i la fantasia no desdibuixen ni molt menys la versemblança dels relats perquè «els personatges de la manufactura escartiana esdevindran espectadors d'uns moments històrics - ficcionats- identificables de l'edat moderna valenciana». Escartí, per tant, «parla d'un període històric (...) però sota un prisma que de vegades ratlla l'irreal i l'absurd» (Borràs 1989: 13) i, alhora, ens fa observar «el passat a través dels ulls d'un subjecte dels segles XVI, XVII i XVIII» (Herrero 2015: 289-290), i fins i tot del XIX i del XX, amb El mas de les ànimes -des del 1799 fins al 1936, començament de la Guerra Civil-i Naumàquia -a les acaballes del segle XX-, respectivament.

Nofra i dona Dolcina presenten un component màgic que gairebé supera el de la resta de subjectes escartians. Tant és així que no és tan desgavellat pensar que Nofra-dona Dolcina és el mateix personatge que pren diferents vides i figures, que apareix i desapareix en diferents relats perquè la màgia i la fantasia no desdibuixen allò que és essencial: «los personajes tienen que ser persones singulares que hagan cosas concretes, en un espacio dado y durante un tiempo determinado» (Cañelles 1999: 94). Fins i tot, si en fem una anàlisi dins del món cinematogràfic ${ }^{31}$ podria encaixar en una sèrie de pel lícules que juguen amb la diversitat de rols -salvant les distàncies, una mena de Clint

però de faccions elegants i primes, solament endevinat la major part de les vegades rere les teles finíssimes que sempre portava (...) i que (...) no es llevava mai» (Escartí 2009: 153-154), «una dama molt alta que semblava anar vestida tota de blanc (...) que caminava amb pas majestuós» (Escartí 2009: 162).

29 Vegeu Herrero (2007a: 250-251; 2015: 284).

30 Els relats «Epistolari del comte de l'Hortxà» de Barroca mort, Espècies perdudes, Vent de juliol i «El retrat anònim» -ni Naumàquia- no presenten de forma tan acusada eixe referent màgic i fantasiós que sí trobem en la resta de novel les.

31 Considerem que podria ser interessant fer una anàlisi comparativa amb el món cinematogràfic a propòsit del realisme màgic i les interconnexions entre les nissagues. Precisament, Escartí fa una referència directa al cinema en Naumàquia, el primer capítol de la qual parla de «Silvana», personatge que protagonitzava Silvana Mangano en el film italià Riso amaro (1949) de Giuseppe de Santis. 


\title{
M. Ángeles Herrero Herrero. Màgia i fantasia al servei de les nobles nissagues: el cas de Nofra- dona Dolcina en la novel la històrica de Vicent Josep Escartí
}

Eastwood en la «Trilogia del dòlar» («Trilogia dell’uomo senza nome», 1964, 1965 i 1966) de Sergio Leone-, amb les diverses possibilitats d'existència -com el camaleó humà interpretat per Woody Allen en Zelig (1983)-, amb els salts en el temps -com en la trilogia Back to the Future (1985-1990) de Robert Zemeckis- o el transcurs alternatiu de l'existència com - en The Curious Case of Benjamin Button (2008) de David Fincher.

És ben interessant allò que apunta Cañelles (1999: 80, 82) quan assenyala que «la novela ha de desprender -más que ingenio o exquisitez formal- humanidad por los cuatro costados. Los personajes son (...) los responsables son de la coherencia y de la lógica interna del texto». És més:

gracias a esa humanidad resultan creíbles las novelas de García Márquez, pues una vez que nos ha convencido de que sus personajes son seres humanos como nosotros los dejamos ya que vuelen o que vivan trescientos años.

Eixos trets són suficientment acomplerts per Nofra i dona Dolcina, però també per altres personatges amb característiques màgiques en el món escartià com el fill de Gepa de Barroca mort o Maria Celidònia Palop d'El mas de les ànimes. ${ }^{32}$ Per la qual cosa, independentment del component màgic $\mathrm{i}$ fantasiós, hi ha altres element que ajuden a la credibilitat dels personatges com l'empatia. Escartí no els allunya d'aquest tret, al contrari, els en carrega, perquè, com diu Cañelles (1999: 143), cal: «lograr un acercamiento afectivo del lector hacia la narración (...). Por eso es conveniente que (...) nos caiga bien». Aquesta afirmació no és gens gratuïta en el cas del vuitè don Arcàngel Gabriel en L'abellerol mort: quan és desemmascarat per dona Dolcina, la simpatia que sentíem per ell es trasllada a la seua antagonista. El lector se sent més a prop de la dona misteriosa que no pas d'un parricida. I ací apareix una altra qualitat que és indestriable d'aquests dos subjectes: la imprevisibilitat (Cañelles 1999: 222). ${ }^{33}$ Així, per una banda, ens topem amb la culpabilitat de n'Arcàngel Gabriel i, per una altra, la confessió de dona Dolcina sobre la seua llarga existència:

\begin{abstract}
-Eren altres temps, don Gabriel. I jo no em pintava com ara. (...) Ara ja soc una ànima del passat, potser; i no sé quin futur m’espera... En aquell temps, també era més fàcil fer certes coses... (...) I així vaig poder prendre la figura i la vida de dona Clemència, i després de dona Nofra, una altra vegada, i més avant de dona Maria, i fins fa uns anys, de dona Trànsit i, a la fi, de dona Dolcina... Allà vaig viure tots els anys que vaig voler, heretant-me a mi mateixa.
\end{abstract}

D’aquesta manera, Nofra-dona Dolcina flueixen per l'univers escartià, perquè «la vida és un continuat i extens pelegrinatge i no sempre hi ha respostes que ens puguen aclarir per quins motius

32 O Miquel Palop d'El mas de les ànimes, qui dorm al llarg de nou mesos durant tot l'embaràs de Maria l'Alemanya i que tingué com a fruit la naixença de la protagonista Maria Celidònia Palop. Vegeu Escartí (2019: 62-67).

33 Una qualitat que Escartí atorga també a altres personatges com, per exemple, Melcior d’Agramunt, protagonista d'Els cabells d'Absalom. 


\title{
M. Ángeles Herrero Herrero. Màgia i fantasia al servei de les nobles nissagues: el cas de Nofra- dona Dolcina en la novel la històrica de Vicent Josep Escartí
}

hem estat ací o allà, en un temps o en un altre» (Escartí 2009: 193). Així ho simbolitza en la novel la de mà del vuitè Arcàngel:

\begin{abstract}
em vaig abocar a la finestra (...). Vaig poder comprovar que l'abellerol seguia allà, sec, momificat. Ja m'havia acostumat a veure'l i ni tan solament em molestava. No entenia per què algun criat no l'havia llevat d'allà. Però devia ser perquè cap d'ells no eixia a aquella balcó. El vaig mirar de nou i vaig descobrir que al seu costat hi havia una llagosta menuda i resseca també, però viva (Escartí 2009: 188).
\end{abstract}

És, aquesta, una metàfora de la mort focalitzada en l'assassinat del seté Arcàngel en el relat, i que plana gairebé de manera implacable per tota la seua obra. I és que l'autor ofereix «una visió apocalíptica de l'existència humana -o, més exactament, escatològica.» (Herrero 2007a: 342). Aquesta concepció de la vida arriba al seu punt àlgid en la seua darrera novel la, El mas de les ànimes, en què la impregna de principi a fi: la seua protagonista, Maria Celidònia Palop, en el seu soterrar, després d'haver viscut vora cent quaranta anys, fa un recorregut per tots aquells personatges de qui ha tingut coneixement durant la seua llarga vida. Aquesta novel la és un dels relats més sòlids de l'autor per la seua qualitat literària, el domini de la tècnica narrativa i un treball minuciós en la construcció dels personatges. A més a més, està carregada d'un fort component màgic i fantasiós que no desdibuixa la complexa i versemblant teranyina de subjectes que transiten per les seues pàgines.

Nofra i dona Dolcina són coneixedores -i còmplices- dels assassinats comesos en els dos relats. Són, al cap i a la fi, unes llagostes com les que les acompanyen en llurs respectives desaparicions:

\begin{abstract}
quan de bell nou vaig poder obrir els ulls i vaig tenir la suficient capacitat per tan d'entendre allò que passava, vaig veure com les llagostes acabaren formant un remolí de vent fortíssim i que, en prendre el vol (...) s'aixecaren amb tanta violència que s'emportaren amb elles el cos de mossèn Jordi (...). Però ni caigué el cos carbonitzat del rector ni la pobra de Nofra, a la qual (...) també se l'havia enduta la nuvolada de les llagostes, carregada com anava amb els ossos del meu notari (Escartí 1993: 150-151).
\end{abstract}

Les llagostes, fora, es veien passar, en nuvolades menudes, arrossegades pels bufits de les ventades que no deixaven de sonar. Les campanes, de nou, tocaven a morts. Dona Dolcina, un instant després ja la vaig poder veure coberta de llagostes. (...) s'envolava davant de mi, i em resultà incomprensible encara. S'elevà i va desaparéixer, com si les llagostes que tenia sota els peus (...) li bastassen per a fer-la volar així, emportant-se-la. (Escartí 2009: 239-241).

Mentre que don Jeroni Joan confessa: «I jo, que en tot açò vaig veure de seguida la mà de Déu, encara ho puc constatar més, ara, en haver passat els anys» (Escartí 1993: 151), el vuitè Arcàngel, un subjecte amb una visió escèptica de l'existència i allunyada de l'alé religiós i del supersticiós declara «ho vaig veure tot, ben vist. Ho vaig presenciar directament, perquè s'esdevingué tot al meu davant. (...) No podia creure, en aquell moment, res, i, tanmateix, ho havia vist» (Escartí 2009: 241). La reacció dels dos protagonistes a tals esdeveniments són, lògicament, contraposades. Un signe 


\section{M. Ángeles Herrero Herrero. Màgia i fantasia al servei de les nobles nissagues: el cas de Nofra- dona Dolcina en la novel la històrica de Vicent Josep Escartí}

més de la versemblança amb què defineix Escartí els seus personatges. Però, a pesar de semblar un personatge immortal, Escartí dota Dolcina d'humanitat (Cañelles 1999: 80): pot ser la dona que permetrà la preservació de la nissaga malgrat els pensaments reticents del vuitè Arcàngel:

\footnotetext{
-Don Gabriel, estic prenyada de vós. Porte al ventre un fill vostre.

(...) En la meua ment es va representar, en aquell moment, el meu fill, el meu fill també Arcàngel i de pell obscura, com la mare. (...)Vaig pensar, per un moment, quines coses dirien tots el meus nobles amics de la cort, en veure aparèixer allà, aquell meu fill, vestit a la francesa, i negre com un carbó (Escartí 2009: 238).
}

Davant d'aquesta notícia, el lector no s'escandalitzarà, ni molt menys, si dona Dolcina, amb aquest nom o sota qualsevol altre, apareix en un futur relat de l'autor algemesinenc.

\section{Conclusions}

Al llarg d'aquestes línies hem volgut evidenciar el ric i complex món literari escartià. L'anàlisi a través de Nofra-dona Dolcina ens ha valgut per a exemplificar com Escartí basteix de forma acurada i precisa els seus relats. El repàs per l'empremta de les dues nissagues principals -els Roger i els Arcàngel de Sant Esteve- no ha estat gratuit per la nostra part. D’una altra manera no es podria explicar el seu univers $i$ entendre quin paper hi interpreten uns personatges singulars que personifiquen extraordinàriament el realisme màgic. De fet, ens situen «davant la màgia com a ingredient importantíssim de la realitat», que distorsiona «el sentit comú» i la contemplen «-crua i amarga- sota la carpa d'un circ on sabem, des que entrem, que tot és dominat per la màgia i la il lusió òptica» (Borràs 1989: 13).

Independentment de si parlem de personatges distints o d'un únic personatge calidoscòpic, Nofradona Dolcina ens han confirmat que Escartí és coherent de principi a fi amb la seua línia novel lística. Aquesta aproximació ens ha posat al davant dos personatges que han resultat arquetípics i coherents amb el conjunt de la seua obra: don Jeroni Joan Roger i el vuitè n'Arcàngel de Sant Esteve. Aquests exemplifiquen una visió contraposada d'un esdeveniment semblant i, alhora, personifiquen la doble òptica que fluctua en el seu món literari: la de l'ambientació històrica versemblant explicada a través de la tradició, la religió i la superstició o de l'escepticisme, segons el relat. Però, al capdavall, hi ha fets inexplicables o que tampoc no necessiten d'una explicació perquè, com manifesta el vuité Arcàngel Gabriel, el món és «inabastable». En definitiva, personatges com Nofra-dona Dolcina patentitzen que el joc amb la màgia i la fantasia és tan important com la construcció d'uns subjectes sòlids que, tot i ser absolutament ficticis, els podríem considerar dignes referents del nostre passat. 
M. Ángeles Herrero Herrero. Màgia i fantasia al servei de les nobles nissagues: el cas de Nofradona Dolcina en la novel la històrica de Vicent Josep Escartí

\section{Bibliografia}

Cañelles, Isabel (1999) La construcción del personaje literario. Un camino de ida y vuelta, Madrid, Ediciones y Talleres de Escritura Creativa Fuentaja.

Escartí, Vicent J. (1988) Barroca mort, Alzira, Bromera (Els Nostres Clàssics), 1989 (3a edició, a cura de Vicent Borràs).

—. (1989) Vent de juliol, Alzira, Fundació Bromera/El Mundo-Levante EMV (Col lecció «Llegir en valencià)), 2006.

—_. (1992) Dies d'ira, Alzira, Bromera (L'Éclèctica), 1993 (3a edició).

—_. (1996) Els cabells d'Absalom, València, Tres i Quatre.

- (1997) Espècies perdudes, València, Tres i Quatre.

—. (2002) Nomdedéu, Alzira, Bromera (L’Eclèctica).

_. (2004) Naumàquia, València, Edicions Tàndem.

- (2009) L'abellerol mort, Alzira, Bromera (L'Eclèctica).

—. (2016) «El retrat anònim», El Mundo [relat en línia, I https://bit.ly/35qY0ru; II https://bit. ly/2OCY6X8; III https://bit.ly/35qY0ru].

- (2019) El mas de les ànimes, Alzira, Bromera (L'Eclèctica).

Herrero Herrero, María de los Ángeles (2004) «Un model d'estructura epistolar en la narrativa de Vicent J. Escartí: anàlisi de Barroca mort», en Epistola i Literatura, Denes, Alacant/València, pp. 359-368.

- (2007a): «A manera de fer memòria del passat valencià: les novel les històriques de Vicent Josep Escartí», en Arxius, memòria i literatura. Actes de les Jornades culturals d'Algemesí, 3 i 4 d'abril de 2003, Algemesí, Ajuntament d'Algemesí, pp. 249-263.

—_. (2007b): «Un dietari en l'exili dins l'univers novel lesc de Vicent Josep Escartí: el cas d'Espècies perdudes (1997)», en Diaris i Dietaris, Denes, Alacant/València, pp. 335-343.

—. (2015): «Els Roger i els Arcàngels: les nobles nissagues del món escartià o la maquinària de construcció de biografies fictícies per Vicent J. Escartí», en Joaquim Espinós, Antoni Maestre i Isabel Marcillas (ed.) La biografia a examen, Barcelona: Publicacions de l'Abadia de Montserrat, pp. 279-291.

Lejeune, Philippe (1994) Elpacto autobiográfico y otros estudios, Madrid, Megazul-Endymion.

Mulet i Grimalt, Carles (1991) «El punt de vista femení a l'obra literària de Maria Ibars», L'Aiguadolc, Núm. 16-17, pp. 41-60.

Sánchez Alonso, Fernando (1998) «Teoría del personaje narrativo (Aplicación a El amor en los tiempos del cólera)», Didáctica. Lengua y Literatura. 10 (ene. 1998), pp. 79-105.

Simbor, Vicent (1996): «Sobre la novel la històrica actual», Caplletra, 22, pp. 105-128. 
M. Ángeles Herrero Herrero. Màgia i fantasia al servei de les nobles nissagues: el cas de Nofradona Dolcina en la novel la històrica de Vicent Josep Escartí

SCRIPTA, Revista internacional de literatura i cultura medieval i moderna, núm. 14/desembre 2019/ pp. 316 - 328 ISSN: 2340-4841 ·doi:10.7203/SCRIPTA.14.16373 